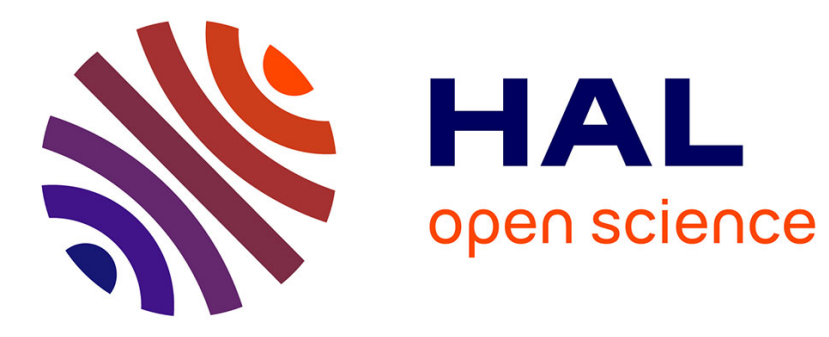

\title{
Four lignans from Portulaca oleracea L. and its antioxidant activities
}

Yifei Ma, Yongrui Bao, Wenjie Zhang, Xixiang Ying, Didier Stien

\section{To cite this version:}

Yifei Ma, Yongrui Bao, Wenjie Zhang, Xixiang Ying, Didier Stien. Four lignans from Portulaca oleracea L. and its antioxidant activities. Natural Product Research, 2019, pp.1-7. 10.1080/14786419.2018.1534852 . hal-02331915

\section{HAL Id: hal-02331915 https://hal.science/hal-02331915}

Submitted on 24 Oct 2019

HAL is a multi-disciplinary open access archive for the deposit and dissemination of scientific research documents, whether they are published or not. The documents may come from teaching and research institutions in France or abroad, or from public or private research centers.
L'archive ouverte pluridisciplinaire HAL, est destinée au dépôt et à la diffusion de documents scientifiques de niveau recherche, publiés ou non, émanant des établissements d'enseignement et de recherche français ou étrangers, des laboratoires publics ou privés. 
Four lignans from Portulaca oleracea L. and its antioxidant activities

Yifei Ma ${ }^{a}$, Yongrui Bao ${ }^{a}$, Wenjie Zhang ${ }^{a}$, Xixiang Ying ${ }^{a}$ and Didier Stien ${ }^{b}$

'School of Pharmacy, Liaoning University of Traditional Chinese Medicine, Dalian, P. R. China;

borbonne Universités, UPMC Univ Paris 06, CNRS, Laboratoire de Biodiversité et Biotechnologies Microbiennes (LBBM), Paris, France

\section{ABSTRACT}

A new lignan, named oleralignan (1) and three known compounds

(+)-syringaresinol (2), (+)-lirioresinol A (3) and monomethyl

3,30,4,40-tetrahydroxy- $\delta$-truxinate (4) were isolated from the $P$. oleracea for the first time. The compound (1) were identified by 1D, 2D NMR spectroscopic methods and high resolution electrospray ionization time-of-flight mass spectrometry. In addition, it was found that the four lignans presented the scavenging activities in 1,1-diphenyl-2-picryl-hydrazyl (DPPH) radical quenching assay more than that of hydroxyl anisole (BHA). 


\section{KEYWORDS}

Portulaca oleracea L.; lignans; antioxidant activity

\section{Introduction}

Portulaca oleracea L. belonging to the family of Portulacaceae, was widely used as a potherb in the Mediterranean, Central European and Asian countries, which was listed in the World Health Organization as one of the most used medicinal plants and has been given the term 'Global Panacea' (Wu et al. 2012). As a traditional Chinese medicine, it is well-known for the function of removing heat, counteracting toxicity, cooling blood, hemostasia and antidysentery (The Pharmacopoeia Commission of PRC 2015). At the same time, it also exhibits a wide range of pharmacological effects, such as antiinflammatory (Meng et al. 2016), antibacterial (Chan et al. 2015), antioxidant (Dkhil et al. 2011), wound-healing activities (Rashed et al. 2003), antitumor (Shen et al. 2013) attributing to its components, i.e., alkaloids (Li et al. 2017; Xu et al. 2017; Zhao et al. 2018; Jiang et al. 2018; Xiu et al. 2018), flavonoids (Yang et al. 2018), phenolic acids (Erkan 2012), terpenoids (Acedo et al. 2012), coumarins (Awad 1994), a-linolenic acid, b-carotenend (Liu et al. 2000) and trace elements (Petropoulos et al. 2015) etc. Recently, the lignans 
was found from the Portulaca oleracea L. for the first time in our laboratory including a new lignan, together with 3 known lignans isolated from the Portulaca oleracea $\mathrm{L}$. for the first time (Figure 1). Lignans and norlignans constitute abundant classes of phenylpropanoids, and these compounds have received widespread interest, mainly because they have various clinically important biological activities (Suzuki and Umezawa 2007), such as antitumour, antioxidant, antimitotic, antiviral activity and etc. (Raghavendra et al. 2015). Therefore, its antioxidant activities against DPPH free radical-scavenging was investigated, and butylated hydroxyanisole (BHA) is being as the antioxidant that is similar to lignans with the phenolic hydroxyl groups as a free radical absorbents (Rahmatzadeh et al. 2017). 


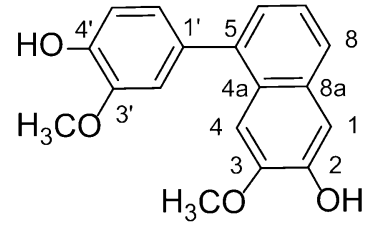

oleralignan $(\mathbf{1})$

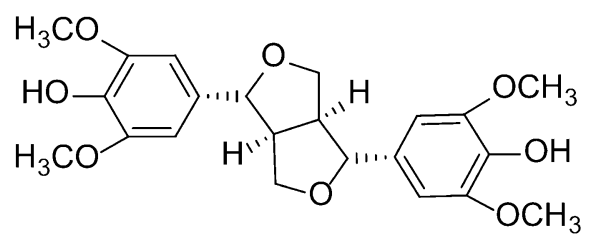

$(2)$<smiles>COc1cc(C2OC[C@@H]3[C@H]2CO[C@H]3c2cc(OC)c(O)c(OC)c2)cc(OC)c1O</smiles>

(3)<smiles>CC(=O)C1C(C(=O)O)C(c2ccc(O)c(O)c2)C1C(=O)O</smiles>

$\left({ }^{4}\right)$

Figure 1. Structure of compounds 1-4.

\section{Results and discussion}

\subsection{Structure elucidation}

Compound 1 was obtained as yellow green powder and turned cyan after spraying ferric chloride. Its molecular formula was identified as $\mathrm{C}_{18} \mathrm{H}_{16} \mathrm{O}_{4}$ based on a molecular ion peak at $\mathrm{m} / \mathrm{z} 297.1093[\mathrm{M}+\mathrm{H}]^{+}$in the HR-ESI-TOF-MS (calcd. for $\mathrm{C} 18 \mathrm{H} 1704,297.1121)$. The degrees of unsaturation of compound 1 were

11. Examination of ${ }^{1} \mathrm{H}$ NMR, DEPT and HMQC led to conclude that compound 1 has 9 aromatic or olefinic $\mathrm{CH}$ and 2 singlet ${ }^{1} \mathrm{H}$ signals corresponding to methoxy groups at $\delta_{H} 3.73$ and 3.80 with carbons at $\delta_{C} 55.1$ and 55.6, 
respectively. Compound 1 also has 8 non-protonated carbons between $\delta$ 126.1 and 148.9. A 3-spin system defined based on proton coupling patterns and on the COSY experiment incudes protons at $\delta 7.15(\mathrm{H}-6), 7.28(\mathrm{H}-7)$ and $7.58(\mathrm{H}-8)$ and defines a 1,2,3-trisubstituted phenyl ring. $\mathrm{H}-6$ and $\mathrm{H}-8$ both correlate with a carbon at d 126.1 which must be attributed to C-4a. Quaternary carbons C-8a $(\delta 129.8)$ and C-5 $(\delta 138.2)$ can be assigned based on their $\mathrm{HMBC}$ correlation with $\mathrm{H}-7$. Correlation $\mathrm{H}-8 / \mathrm{C}-1$, correlations of $\mathrm{H}-1$ with $\mathrm{C}-2, \mathrm{C}-3, \mathrm{C}-4 \mathrm{a}$ and $\mathrm{C}-8$, and correlations of $\mathrm{H}-4$ with $\mathrm{C}-2, \mathrm{C}-3, \mathrm{C}-5, \mathrm{C}-8 \mathrm{a}$ define another tetrasubstituted fused aromatic ring. A methoxy group can be placed in $\mathrm{C}-3$ based on $\mathrm{MeO} / \mathrm{C}-3$ correlation and the weak COSY correlation of the methyl group with $\mathrm{H}-4$. The molecular formula and the carbon chemical shift indicate that C-2 bears a hydroxyl group. Another 3-spin system was found based on ${ }^{1} \mathrm{H}-{ }^{1} \mathrm{H}$ coupling pattern and COSY experiment. It includes protons at $\delta$ $7.03\left(\mathrm{H}-2^{\prime}\right), 6.91\left(\mathrm{H}-5^{\prime}\right)$ and $6.90\left(\mathrm{H}-6^{\prime}\right)$ and defines a 1,3,4-tribstituted aromatic ring. A methoxy group was placed in $\mathrm{C}^{-} 3^{\prime}$ based on correlation $\mathrm{H}-5^{\prime} / \mathrm{C}-3^{\prime}$ and on the correlation of the methyl protons with $\mathrm{C}-3^{\prime}$. A hydroxyl substituent should therefore be in C-4'. Eventually, this additional phenyl ring was connected to $\mathrm{C}-5$ based on the correlations $\mathrm{H}-6 / \mathrm{C}-\mathrm{1}^{\prime}$ and $\mathrm{H}-2^{\prime} / \mathrm{C}-5$. As a result, compound 1 was identified as the 5-(4-hydroxy-3-methoxyphenyl)-3-methoxynaphthalen-2-ol and was given the trivial name oleralignan (1). 
By comparison of the ${ }^{1} \mathrm{H}$ and ${ }^{13} \mathrm{C}$ NMR spectral data with literature, compounds 2-4 were identified as the (+)-syringaresinol (2) (Monthong et al. 2011), (+)-lirioresinol A (3) (Liu et al. 2013), monomethyl 3,3',4,4'-tetrahydroxy- $\delta$-truxinate (4) (Liang et al. 2015), respectively.

\subsection{Antioxidant activity}

The DPPH radical scavenging method (Xiong et al. 1996) was used to determine the antioxidant activities of the compounds, which was improved to evaluate the four lignans isolated from $P$. oleracea. The results indicated that the four lignans presented higher antioxidant activity than that of BHA (Table S2 in supplementary material) because of its more phenolic hydroxyl group around the lignans framework playing an important role in scavenging DPPH radical (Miyake et al. 2005). Figure S17 showed that the antioxidant activities of the four lignans were dose-dependent.

\section{Experimental}

3.1. General experimental procedures

UV spectrum was obtained from a HITACHI U-3010 spectrophotometer (Hitachi Ltd, Tokyo, Japan), the IR spectrum and data obtained from IR200 
spectrophotometer (Thermo Electron Corporation, Waltham, MA). The NMR spectra in DMSO- $d_{6}$ or MeOD was recorded by using an AVANCE $500 \mathrm{MHz}$ instrument (Bruker Corporation, Switzerland). Relative molecular mass was recorded using a 6520 quadrupole-time-offlight mass spectrometer (Agilent, Palo Alto, CA). Purity was detected on a Nexera X2 UHPLC LC-30A system (Shimadzu, Kyoto, Japan), using a Kromasil C18 column (150 mm x $4.6 \mathrm{~mm}, 5$ $\mathrm{mm}$, Dalian Johnsson Separation Science and Technology Corporation). In the separation process, column chromatography (CC) included silicagel (100-220 and 200-300 mesh, Qingdao Marine Chemical Co., Qingdao, China), polyamide resin (80-100 mesh, Taizhou Luqiao Sijia Biochemical Plastic Factory, Zhejiang, China) and ODS (20-40 Im, GE Healthcare, Marlborough, MA). The TLC was prepared with silica gel GF254 (Qingdao Marine Chemical Co., Qingdao, China).

\subsection{Plant materials and chemicals}

The whole herbs of P. oleracea were collected in Shijiazhuang (Hebei, China) in June 2017, and identified by Prof. Xixiang Ying. The voucher specimen (No. 20171001) was displayed at Liaonig University of Traditional Chinese Medicine. 1,1-Diphenyl-2-picrylhydrazyl radical (DPPH) (purity $\geq 99 \%$ ) was purchased from Sigma Co. (USA). BHA (purity $\geq 98 \%$ ) was purchased from Shanghai Xiangrui Biological Technology Co., Ltd. (Shanghai, China). Methanol, acetonitrile and formic acid are all of HPLC grade provided by Damao Chemical 
Reagent Plant (Tianjin, China, purity $\geq 99.9 \%$ ). All other reagents were of analytical grade purchased from Jinfeng Chemical Factory (Tianjin, China), and the water was WAHAHA purified water (Shenyang, China).

\subsection{Isolation and identification}

A sample $(150 \mathrm{~kg})$ of the air-dried aerial parts $P$. oleracea was treated twice with 10 volumes of water for 2 hours each time to afford a crude extract ( 21 $\mathrm{kg})$. The extract was concentrated and subjected to a 100-200 mesh silica-gel column chromatography ( $61 \times 55 \mathrm{~cm}$, approximately, $150 \mathrm{~kg}$ ) with a 2 volumes of ethyl acetate 3 times as the isocratic elution, affording the fraction evaporated $(180 \mathrm{~g})$. Then, the fraction eluted with water, 30\%, 50\%, 70\% and pure ethanol was chromatographed respectively on a 80-100 mesh polyamide resin column ( $120 \times 8 \mathrm{~cm}$, approximately, $2.5 \mathrm{~kg}$ ) to obtain five fractions (4 L each). The fraction of $50 \%$ extracting was condensed under the reflux to obtain the extract of $58 \mathrm{~g}$, which was subjected to a 200-300 mesh silica-gel column (120 x $8 \mathrm{~cm}$, approximately, $2.5 \mathrm{~kg}$ ) for further purification with ethyl acetate, ethyl acetate and methanol $(5: 1,2: 1,1: 2,1: 4, v / v)$ as the gradient eluant, obtaining five fractions (Frs. 1-5, $500 \mathrm{~mL}$ each). The fractions (38 g), which turns cyan when exposed to ferric chloride reagent, were applied to an ODS column chromatography (20-40 Im, $150 \mathrm{~g}$, Ultimate XB-C18, u3 x $70 \mathrm{~cm}$ ) and eluted with methanol $(40 \%, 50 \%, 60 \%, 70 \%$, respectively). At medium pressure, five fractions (A1-A5, $100 \mathrm{~mL}$ each) were obtained. $\mathrm{A} 3(0.46 \mathrm{~g})$ was 
changed to cyan when exposed to ferric chloride reagent, and then purified on a Sephadex LH-20 column $(100 \mathrm{~g}, \mathrm{u} 2 \times 150 \mathrm{~cm})$ using methanol solvent to give fractions B1-B6, and then B3 was prepared by ultra-high performance liquid chromatography (UHPLC), using Acetonitrile- $0.1 \%$ formic acid as the mobile phase, with flow rate of $1.0 \mathrm{~mL} / \mathrm{min}$, and obtained compound 1 (4 mg, purity of $>99 \%$ with UHPLC, tR 9.606 min, Acetonitrile-0.1\% formic acid, 40:60, v/v), compound 2 (5 mg, purity of $>98 \%$ with UHPLC, tR 5.94 min, Acetonitrile-water, 30:70, v/v), compound 3 (7 mg, purity of $>98 \%$ with UHPLC, tR $6.07 \mathrm{~min}$, Acetonitrile-0.1\% formic acid, 32:68, v/v), compound 4 (4 mg, purity of $>97 \%$ with UHPLC, tR 28.23 min, $\mathrm{MeOH}-0.1 \%$ formic acid, 10:90, $\mathrm{v} / \mathrm{v})$.

Oleralignan (1): yellow-green powder; UV $\left(\mathrm{CH}_{3} \mathrm{OH}\right) \mathrm{kmax} 291,236 \mathrm{~nm}$; IR ( $\mathrm{KBr}$ ) vmax 3393, 2925, 2850, 1600, 1515, 1478, 1256, 1203, 1159, 1125, 1021, 859, 790, $762 \mathrm{~cm}^{-1} \cdot{ }^{1} \mathrm{H}$ and ${ }^{13} \mathrm{C}$ NMR data (Table S1 in supplementary material); HR-ESI-TOF-MS m/z 297. $1093[\mathrm{M}+\mathrm{H}]^{+}$(calcd. for $\mathrm{C}_{18} \mathrm{H}_{17} \mathrm{O}_{4}, 297.1121$ ).

\subsection{Assay of scavenging DPPH radicals}

Scavenging of DPPH free radical activity was the basis method of the antioxidative activities of determining the compounds (Sharma and Bhat 2009). Each compound has been diluted with methanol to five different concentrations ranging from 2.5 to $40 \mu \mathrm{M}$, and $\mathrm{BHA}$ as the positive control 
was also diluted to the same concentrations. Thereafter, the different concentrations of sample and BHA (1 mL) was separately mixed with $80 \mu \mathrm{M}$ DPPH (1 mL) which dissolved in methanol. The methanol was used to zero the spectrophotometer. The mixtures were allowed to stand for $20 \mathrm{~min}$, and measured at $517 \mathrm{~nm}$ at room temperature. The DPPH solution $(1 \mathrm{~mL})$ added to methanol $(1 \mathrm{~mL})$ were used as the blank group. The sample solution $(1 \mathrm{~mL})$ and methanol $(1 \mathrm{~mL})$ were used as the control group. Each sample was examined five times in parallel. Radical scavenging activity was expressed as the clearance percentage and calculated using the following formula (Mensor et al. 2001):

DPPH radical scavenging effect $(\%)=\left(1-\left(A_{\text {sample }}-A_{\text {control }}\right) /=A_{\text {blank }}\right) \times 100 \%$ where, $A_{\text {control }}$ is the absorbance of the control group, $A_{\text {sample }}$ is the absorbance of the test compound, and $A_{\text {blank }}$ is the absorbance of the blank group. The antioxidant capacities were evaluated by the values of $\mathrm{IC}_{50}$, and values are expressed as the means \pm SD for $n=5$.

\section{Conclusion}

In this study, the lignans was found in the Portulaca oleracea L. for the first time including a new lignans named oleralignan (1), together with three known compounds $\mathbf{2}, \mathbf{3}$ and $\mathbf{4}$ isolated from the plant for the first time. The antioxidant activity assay indicated that the compound 1, 2, 3 and 4 showed more stronger activities of scavenging DPPH radical than that of $\mathrm{BHA}$, with $\mathrm{IC}_{50}$ 
value of $20.64,17.34,16.46$ and $8.00 \mu \mathrm{M}$, respectively.

\section{Disclosure statement}

The authors have no conflicts of interest to disclose.

\section{Funding}

This work was supported by the National Natural Science Foundation of China (Grant 81573546).

\section{References}

Acedo JZ, Reyes CT, Rodriguez EB. 2012. Chemical composition of purslane (Portulaca oleracea L.) and anti-inflammatory activity of its lipid components. Philipp J Crop Sci. 37:13-19.

Awad NE. 1994. Lipid content and antimicrobial activity of phenolic constituents of cultivated Portulaca oleracea L. Bull Fac Pharm Cairo Univ. 32:137-142.

Chan BCL, Han XQ, Lui SL, Wong CW, Wang TBY, Cheung DWS, Cheng SW, Ip M, Han SQB, Yang X-S, et al. 2015. Combating against methicillin-resistant Staphylococcus aureus - two fatty acids from Purslane (Portulaca oleracea L.) exhibit synergistic effects with erythromycin. J Pharm Pharmacol. 67(1):107-116. 
Dkhil MA, Moniem AEA, Al-Quraishy S, Saleh RA. 2011. Antioxidant effect of purslane (Portulaca oleracea) and its mechanism of action. J Med Plants Res. 5:1563-1589.

Erkan N. 2012. Antioxidant activity and phenolic compounds of fractions from Portulaca oleracea L. Food Chem. 133(3):775-781.

Jiang MY, Zhang WJ, Yang X, Xiu F, Xu HR, Ying XX, Stien D. 2018. An isoindole alkaloid from Portulaca oleracea L. Nat Prod Res. 32(20):2431-2436. Li CY, Ying ZM, Gao MZ, Wei WJ, Hao D, Xu L, Tao XJ, Zhang WJ, Ying XX, Liu J. 2017. Two new similar alkaloids from Portulaca oleracea L. Nat Prod Res. 31(15):1792-1798.

Liang D, Liu YF, Hao ZY, Luo H, Wang Y, Zhang CL, Chen RY, Yu DQ. 2015. Acylated flavonol glycosides and $\delta$-truxinate derivative from the aerial parts of Lysimachia clethroides. Phytochem Lett. 11:116-119.

Liu L, Howe P, Zhou YF, Xu ZQ, Hocart C, Zhan R. 2000. Fatty acids and beta-carotene in australian purslane (Portulaca oleracea) varieties. J Chromatogr A. 893(1):207-213.

Liu Q, Li J, Chai X, Jiang Y, Tu P. 2013. Chemical constituents from qianliang tea. J Pharm Sci US. 22:427-430. 
Meng YH, Ying ZM, Xiang Z, Hao D, Zhang WJ, Zheng Y, Gao YC, Ying XX. 2016. The anti-inflammation and pharmacokinetics of a novel alkaloid from Portulaca oleracea L. J Pharm Pharmacol. 68(3):397-405.

Mensor LL, Menezes FS, Leitão SG. 2001. Screening of Brazilian plant extracts for antioxidant activity by the use of dpph free radical method. Phytother Res. 15(2):127-130.

Miyake Y, Fukumoto S, Okada M, Sakaida K, Yoshimasa Nakamura A, Osawa T. 2005. Antioxidative catechol lignans converted from sesamin and sesaminol triglucoside by culturing with aspergillus. J Agric Food Chem. 53(1):22-27.

Monthong W, Pitchuanchom S, Nuntasaen N, Pompimon W. 2011.(p)-syringaresinol lignan from new species Magnolia thailandica. Am J Appl Sci. 8:1268-1271.

Petropoulos SA, Karkanis A, Fernandes Â, Barros L, Ferreira ICFR, Ntatsi G, Petrotos K, Lykas C, Khah E. 2015. Chemical composition and yield of six genotypes of common purslane (Portulaca oleracea L.): an alternative source of omega-3 fatty acids. Plant Foods Hum Nutr. 70(4):420-426.

Raghavendra KR, Kumar KA, Shashikanth S. 2015. An efficient synthesis of new lignan scaffolds as antimicrobial inhibition agents. J Chem Pharm Res. 
7:638-644.

Rahmatzadeh M, Kohram H, Zare SA, Seifi-Jamadi A, Ahmad E. 2017. Antioxidative effect of BHA in soya bean lecithin-based extender containing glycerol or dmso on freezing capacity of goat semen. Reprod Domest Anim. 52(6):985-991.

Rashed AN, Afifi FU, Disi AM. 2003. Simple evaluation of the wound healing activity of a crude extract of Portulaca oleracea L. (growing in Jordan) in Mus musculus JVI-1. J Ethnopharmacol. 88(2-3):131-136.

Sharma OP, Bhat TK. 2009. DPPH antioxidant assay revisited. Food Chem. 113:202-1205.

Shen H, Tang G, Zeng G, Yang Y, Cai X, Li D, Liu HC, Zhou NX. 2013. Purification and characterization of an antitumor polysaccharide from Portulaca oleracea L. Carbohydr Polym. 93(2):395-400.

Suzuki S, Umezawa T. 2007. Biosynthesis of lignans and norlignans. J Wood Sci. 53(4):273-284.

The Pharmacopoeia Commission of PRC. 2015. The pharmacopoeia of the People's Republic of China (Part 1). Beijing: China Medical Science and Technology Press, p. 49-50. 
Wu B, Yu L, Wu X, Chen J. 2012. New $\mathrm{CuCl}_{2}$-induced glucoside esters and other constituents from Portucala oleracea. Carbohydr Res. 351:68-73.

Xiong Q, Kadota S, Tani T, Namba T. 1996. Antioxidative effects of phenylethanoids from cistanche deserticola. Biol Pharm Bull. 19(12):1580-1585.

Xiu F, Li XT, Zhang WJ, He F, Ying XX, Stien D. 2018. A new alkaloid from Portulaca oleracea L. and its antiacetylcholinesterase activity. Nat Prod Res. doi: $10.1080 / 14786419.2018 .1460833$

Xu L, Ying ZM, Wei WJ, Hao D, Wang HB, Zhang WJ, Li CY, Jiang MY, Ying XX, Liu J. 2017.A novel alkaloid from Portulaca oleracea L. Nat Prod Res. 31(8):902-908.

Yang X, Zhang WJ, Ying XX, Stien D. 2018. New flavonoids from Portulaca oleracea L. and their activities. Fitoterapia. 127:257-262.

Zhao CC, Ying ZM, Tao XJ, Jiang MY, Ying XX, Yang GL. 2017. A new lactam alkaloid from Portulaca oleracea L. and its cytotoxity. Nat Prod Res. 32:1548-1553. 